\title{
Comparative evaluation of two physically based models for the description of stress-relaxation behaviour of $9 \%$ chromium containing steel
}

\author{
J. Christopher*, C. Praveen, B.K. Choudhary \\ Materials Development and Technology Division, HBNI, Indira Gandhi Centre for Atomic Research, Kalpakkam, Tamil \\ Nadu,603102,India, e-mail:jchris@igcar.gov.in
}

\begin{abstract}
An attempt has been made to evaluate the applicability of two constitutive models related to the dislocation-obstacle interactions for the description of stress-relaxation behaviour of E911 tempered martensitic steel. The first one is Feltham model (Model-I) and the second model proposed by Christopher and Choudhary (Model-II) is based on the sine hyperbolic kinetic rate formulation coupled with the evolution of internal stress. The physical constants associated with these models have been determined by the minimization of errors between experimental and predicted relaxation stress vs. hold time data for two different strain hold levels of 1.3 and $2.5 \%$ at 873 $\mathrm{K}$ for E911 steel. Model-II provides better prediction of stress-relaxation behaviour of the steel as compared to Model-I. In addition to prediction of relaxation stress vs. hold time data, Model-II describes the evolution of internal stress, inter-barrier spacing and activation volume with the hold time. The predicted increase in inter-barrier spacing and activation volume with hold time indicated that substructural coarsening remains dominant in E911 steel under stress-relaxation conditions.
\end{abstract}

KEYwORDS. Feltham model; Sine hyperbolic kinetic rate; E911 steel; Stressrelaxation behaviour

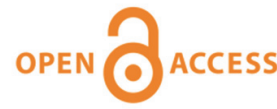

Citation: Christopher, J., Praveen, C., Choudhary, B.K, Comparative Evaluation of Two Physically Based Models for the Description of Stress-Relaxation Behaviour of 9\% Chromium Containing Steel, Frattura ed Integrità Strutturale, 48 (2019) 554-562.

Received: 22.11 .2018

Accepted: 28.02.2019

Published: 01.04.2019

Copyright: (C) 2019 This is an open access article under the terms of the CC-BY 4.0, which permits unrestricted use, distribution, and reproduction in any medium, provided the original author and source are credited.

\section{INTRODUCTION}

9 $\%$ chromium tempered martensitic steels are favoured structural materials for high temperature heat exchanger applications in power generating industries. Among 9\% Cr steels, E911 steel offers good combination of high creep strength and ductility, and microstructural stability over long exposures at elevated temperatures [1]. Understanding and modelling of inelastic deformation behavior of structural materials at elevated temperatures attract continued scientific and technological interest in view of improving the appropriate conditions for material processing and for reliable prediction of the performance of the components during service. Stress-relaxation testing is one of the potential techniques for understanding the high temperature inelastic deformation behaviour of materials [2]. During stressrelaxation testing, the externally imposed constraint i.e. total applied strain $\left(\varepsilon_{t}\right)$, is kept constant. Since the total strain rate is related to the sum of elastic $\left(\varepsilon_{\mathrm{e}}\right)$ and inelastic $\left(\varepsilon_{\text {in }}\right)$ strain components, the total applied strain rate is equal to zero and it is represented as 


$$
\dot{\varepsilon}_{t}=\dot{\varepsilon}_{e}+\dot{\varepsilon}_{\text {in }}=0
$$

Further, the elastic strain rate $\left(\dot{\varepsilon}_{e}\right)$ given in Eqn. (1) is written as

$$
\dot{\varepsilon}_{e}=\frac{\dot{\sigma}_{r}}{C}
$$

The interrelationship between stress-relaxation rate and inelastic strain rate can be obtained from Eqn. (1) and Eqn. (2) as

$$
\dot{\varepsilon}_{i n}=-\dot{\varepsilon}_{e}=-\frac{\dot{\sigma}_{r}}{C}
$$

Eqn. (3) indicates that the decrease in elastic strain is exactly balanced by an increase in inelastic strain during relaxation. This leads to the decrease in stress values with hold time. Eqn. (3) represents a generalised relationship for the description of stress-relaxation behaviour for any materials. In common, developed models for stress-relaxation mainly focus on the interrelationship between inelastic strain rate and relaxation stress. The inelastic strain rate given in Eqn. (3) captures only the creep strain developed during stress relaxation. Time independent part of inelastic strain (i.e. plastic strain) has been assumed to be insignificant in the present investigation. Between the existing models [3], the model proposed by Feltham [4] is widely used to describe the stress-relaxation behaviour of different metals and alloys [4-7]. In this study, in addition to the Feltham model, the relationship recently proposed by Christopher and Choudhary [8] based on the sine hyperbolic kinetic rate formulation coupled with the evolution of internal stress has been employed to describe the stress-relaxation behaviour of materials. The physical constants associated with these models have been determined by the minimization of errors between experimental and predicted relaxation stress vs. hold time data for two different strain hold levels of 1.3 and $2.5 \%$ at $873 \mathrm{~K}$ for E911 steel. Among these two models, the appropriate relationship applicable for the E911 steel has also been identified in this study.

\section{MODELLING FRAMEWORK}

\section{Feltham Relationship for stress-relaxation behaviour (Model-I)}

B ased on kinetic theory of dislocation-local obstacle interaction, Feltham [4] proposed the inelastic strain rate relationship to describe the stress-relaxation behaviour and it is given as

$$
\dot{\varepsilon}_{i n}=\dot{\varepsilon}_{0} \rho_{m} \exp \left(\frac{-\left(Q-\left(\sigma_{r}-\sigma_{i}\right) \Delta V\right)}{k T}\right)
$$

where $\dot{\varepsilon}_{0}$ is the characteristic strain rate that includes a frequency factor, the area swept out by an activated dislocation and the Burgers vector (b) and $\sigma_{\mathrm{r}}-\sigma_{\mathrm{i}}$ is equal to the effective stress $\left(\sigma_{\mathrm{e}}\right)$. According to Feltham [4], the parameters such as characteristic strain rate $\left(\dot{\boldsymbol{\varepsilon}}_{0}\right)$, mobile dislocation density $\left(\rho_{\mathrm{m}}\right)$ and activation volume $(\Delta \mathrm{V})$ are unaltered during deformation under stress-relaxation and the internal stress $\sigma_{\mathrm{i}}$ is assumed as a constant. Eqn. (4) is substituted in Eqn. (3) and integration of Eqn. (3) with appropriate boundary conditions is represented as

$$
\int_{\sigma_{r 0}}^{\sigma_{r}} \exp \left(\frac{\left(Q-\left(\sigma_{r}-\sigma_{i}\right) \Delta V\right)}{k T}\right) d \sigma_{r}=\int_{0}^{t}-C \dot{\varepsilon}_{0} \rho_{m} d t
$$

where $\sigma_{\mathrm{r} 0}$ is the relaxation stress at $\mathrm{t}=0$. Eqn. (5) yields

$$
\sigma_{r}=\sigma_{r 0}-\frac{k T}{\Delta V} \ln \left(1+\frac{t}{t_{0}}\right)
$$


where $\frac{1}{t_{0}}=\frac{C \dot{\varepsilon}_{0} \rho_{m} \Delta V}{k T} \exp \left(\frac{-\left(Q-\left(\sigma_{r 0}-\sigma_{i}\right) \Delta V\right)}{k T}\right)$ with $t_{0}$ is treated as a constant. Eqn. (6) is employed for the description of relaxation behaviour of different materials. In common, the simplified form of Eqn. (6) is represented as

$$
\sigma_{r}=\sigma_{r 0}-s \ln (1+\eta t)
$$

where $s$ and $\eta$ are constants and $s=K T / \Delta V ; \eta=1 / t_{0}$.

\section{SINE HYPERBOLIC RATE MODEL FOR STRESS-RELAXATION BEHAVIOUR (MODEL-II)}

I $\mathrm{n}$ addition to Feltham model (Model-I) [4], recently developed constitutive model for the description of stressrelaxation behavior of P91 steel has also been used to examine the stress-relaxation behaviour of the steel [8]. The model is based on the incorporation of stress dependent activation volume and average dislocation segment length into the kinetic rate theories [8,9]. The final relationship defining the inelastic strain rate in terms of internal stress $\left(\sigma_{\mathrm{i}}\right)$ is represented by

$$
\dot{\varepsilon}_{i n}=\frac{\rho_{m} b^{2} v_{D}\left(\sigma_{r}-\sigma_{i}\right)\left(\sigma_{i}^{2}\left(\sigma_{r}-\sigma_{i}\right)\right)^{-1 / 3}}{M^{2}} \exp \left(\frac{-Q}{R T}\right) \sinh \left(\frac{\left(\sigma_{r}-\sigma_{i}\right)}{M k T} b^{3}\left[\frac{\mu}{\left(\sigma_{i}^{2}\left(\sigma_{r}-\sigma_{i}\right)\right)^{1 / 3}}\right]\right)
$$

The rate equation for the evolution of internal stress with time is derived based on the power law relationship proposed by Argon and Takeuchi [10] and it is given as

$$
\dot{\sigma}_{i}=m\left(\frac{h \sigma_{r}^{m}}{\sigma_{r}}\right) \dot{\sigma}_{r}=m\left(\frac{\sigma_{i}}{\sigma_{r}}\right) \dot{\sigma}_{r}
$$

The coupled differential equations i.e. Eqn.(3), Eqn. (8) and (9) have been used to describe the stress-relaxation beahviour of the materials. There are three unknown constants such as initial relaxation stress $\left(\sigma_{\mathrm{r} 0}\right)$, initial internal stress $\left(\sigma_{\mathrm{i} 0}\right)$ and power law exponent $(\mathrm{m})$ related to internal stress. The power law coefficient (h) given in Eqn. 9 can be obtained as $h=\frac{\sigma_{i 0}}{\sigma_{r 0}^{m}}$.

\section{EXPERIMENAL DATA}

7 he relaxation stress vs. hold time data obtained for E911 steel in normalised and tempered condition has been used in the present investigation. The chemical composition (wt. \%) of E911 ferritic-martensitic steel was as follow as: Fe-0.105C-9.16Cr-1.01Mo-1.0W-0.07Ni-0.20Si-0.35Mn-0.23V-0.068Nb-0.007P-0.003S-0.072N. Normalizing treatment involved austenitizing at $1323 \mathrm{~K}$ for $30 \mathrm{~min}$ followed by air cooling and tempering treatment was performed by soaking at $1023 \mathrm{~K}$ for $1 \mathrm{~h}$ followed by air cooling. TEM microstructure of E911 steel shows the tempered martensitic lath structure accompanied with dense dislocations as depicted in Fig. 1. Cylindrical specimens of $32.5 \mathrm{~mm}$ gauge length and $6.4 \mathrm{~mm}$ gauge diameter were machined from the normalised and tempered specimen blanks. Test specimen dimensions are shown in Fig. 2. Stress-relaxation tests were carried out in air environment (i.e. ambient condition without controlled atmosphere and possibility of air ingress into the furnace environment) at $873 \mathrm{~K}$ in a servohydraulic universal testing system equipped with three-zone-resistance heating furnace and proportional-integral-derivative temperature controller. Three-zone-resistance heating furnace provides much larger uniform temperature zone than the specimen dimension. Calibrated thermocouples were used in conjunction with the appropriate temperature indicating devices and the test temperature was controlled well within $\pm 2 \mathrm{~K}$. Tests were performed by employing nominal loading strain rate of $1 \times 10^{-4} \mathrm{~s}^{-1}$ to the desired total applied strain levels of 1.3 and $2.5 \%$. After 24 hours of hold duration, the 
unloading was performed at the same strain rate of $1 \times 10^{-4} \mathrm{~s}^{-1}$. The diagram for loading pattern is shown in Fig. $3 \mathrm{a}$. Loadelongation data were recorded using data acquisition system for all the tests. From the load-displacement data, the stress vs. strain data was obtained. As an example, Fig. 3 b shows the stress vs. strain diagram for E911 steel at $873 \mathrm{~K}$ for $1.3 \%$ strain hold. Using the stress vs. strain and strain vs. time data, the stress-relaxation data was acquired by judiciously selecting small time intervals in terms of relaxation stress $\left(\sigma_{\mathrm{r}}\right)$ vs. hold time $(\mathrm{t})$. In Fig. 3b, permanent set defines the strain present in the material when it is unloaded to zero stress.

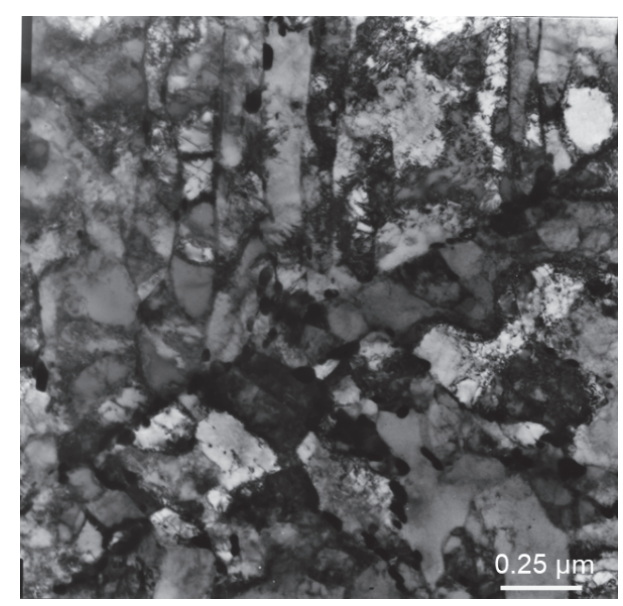

Figure 1: Microstructure of E911 steel in normalised and tempered condition.

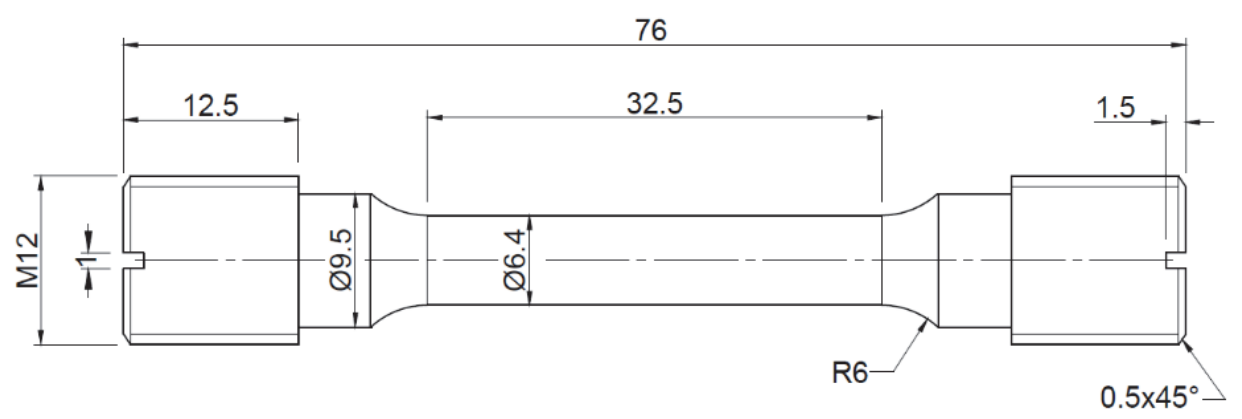

NOTE:

ALL DIMENSIONS ARE IN mm. UNLESS OTHERWISE SPECIFIED.

Figure 2: Specimen geometry used for stress relaxation tests.

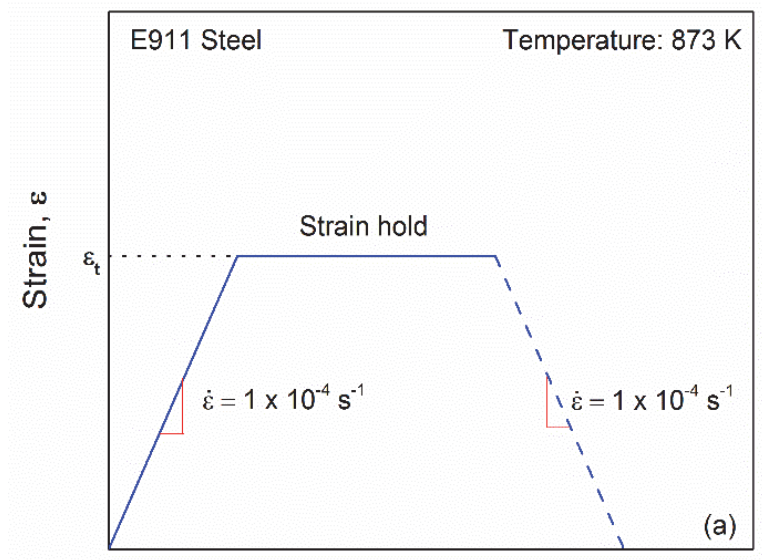

Time, $\mathrm{t}$

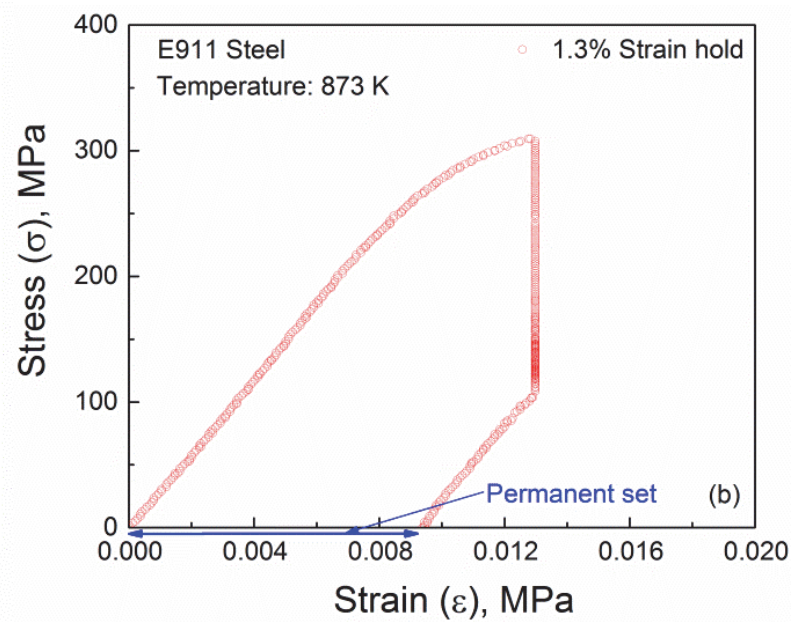

Figure 3: a) Loading waveform for stress relaxation tests and b) Stress-strain curve for strain hold of $1.3 \%$ at $873 \mathrm{~K}$. 


\section{METHODOLOGY FOR PARAMETRIC OPTIMIZATION}

$\mathrm{T}$

he physical constants associated with these models have been determined by the minimization of errors between experimental and predicted relaxation stress vs. hold time data for two different strain hold levels of 1.3 and 2.5\% at $873 \mathrm{~K}$ for E911 steel. In order to obtain the unknown constants such as $\mathrm{s}$ and $\eta$ in Model-I, least-square optimisation based on Levenberg-Marquardt algorithm has been used. Tab. 1 shows the optimised constants associated with the Model-I for E911at $873 \mathrm{~K}$ for the strain holds of 1.3 and 2.5\%. An iterative procedure has been invoked to obtain the constants associated with the Model-II. As a first step in the iteration, random initial value of parameters within the bounds has been seeded for numerical integration. The coupled differential equations (i.e. Eqns. (3), (8) and (9)) defining the of relaxation stress $\left(\dot{\sigma}_{r}=-C \dot{\varepsilon}_{\text {in }}\right)$, inelastic strain and internal stress with time have been numerically integrated by the fourth-order Runge-Kutta method. Following numerical integration, the least-square error value has been estimated and then the parameter values are adjusted using interior-point algorithm for obtaining low least-square error value [9]. The fitting procedure has been repeated for several iterations to reach the optimised parameters. The optimised constants associated with Model-II for E911at $873 \mathrm{~K}$ for the strain holds of 1.3 and $2.5 \%$ have been presented in Tab. 2. For the numerical integration, the values of constants such as $\mathrm{M}=3 ; \mathrm{b}=0.268 \mathrm{~nm} ; \mu=64420 \mathrm{MPa} ; \mathrm{k}=1.38 \times$ $10^{-23} \mathrm{~J} / \mathrm{K} ; v_{\mathrm{D}}=1 \times 10^{13} \mathrm{~s}^{-1}$ and $\mathrm{R}=8.314 \mathrm{~J} \mathrm{~mol}^{-1} \mathrm{~K}^{-1}$ have been considered. The mobile dislocation density values of $1 \times$ $10^{13} \mathrm{~m}^{-2}$ have been chosen for E911 steel [9]. The activation energy value of $285 \mathrm{~kJ} \mathrm{~mol}^{-1}$ has been fixed for E911 steel [11]. For Model-II, the bounds for the physical constants are fixed based on the following consideration. The upper and lower limit values of $\sigma_{\text {ro }}$ were chosen close to the initial relaxation stress. Hence, the bounds are fixed between 275 to 350 MPa. Since initial internal stress $\left(\sigma_{\mathrm{i}}\right)$ should be less than the initial relaxation stress, the bounds for $\sigma_{\text {io }}$ are fixed between 200 to $275 \mathrm{MPa}$. The value of ' $\mathrm{m}$ ' is allowed to vary between 0 and 1 based on the literature values [10]. Once the three unknown independent parameters $\left(\sigma_{\mathrm{ro}}, \sigma_{\mathrm{io}}\right.$ and $\left.\mathrm{m}\right)$ are optimized, the dependent parameter $b$ has been calculated using $h=\frac{\sigma_{i 0}}{\sigma_{r 0}^{m}}$.

\begin{tabular}{rrccc}
\hline \multicolumn{2}{c}{ Parameter } & $\sigma_{\mathrm{r} 0}, \mathrm{MPa}$ & $\mathrm{s}, \mathrm{MPa}$ & $\eta, \mathrm{s}^{-1}$ \\
$\begin{array}{l}\text { Hold } \\
\text { strain } \\
\text { levels }\end{array}$ & $1.3 \%$ & 311.55 & 20.0 & 0.34 \\
\hline
\end{tabular}

Table 1: Optimised parameters associated with the Model-I for E911 steel.

\begin{tabular}{rcccc}
\hline Parameter & $\sigma_{\mathrm{r} 0}, \mathrm{MPa}$ & $\sigma_{\mathrm{i} 0}, \mathrm{MPa}$ & $\mathrm{m}$ & $\mathrm{h}, \mathrm{MPa}$ \\
$1.3 \%$ & 309.55 & 227.08 & 0.812 & 2.15 \\
$2.5 \%$ & 324.68 & 238.97 & 0.809 & 2.22 \\
\hline
\end{tabular}

Table 2: Optimised parameters associated with the Model-II for E911 steel.

\section{RESULTS AND DISCUSSION}

$\mathrm{T}$ he experimental as well as predicted relaxation stress $\left(\sigma_{\mathrm{r}}\right)$-time $(\mathrm{t})$ data have been shown in Fig. 4 as double logarithmic plots for the strain holds of 1.3 and $2.5 \%$ at $873 \mathrm{~K}$. A marginal decrease in relaxation stress with time for the initial hold durations followed by rapid linear decrease in stress values at longer durations has been 
observed in log-log plot for both the strain holds. It can be seen that the predicted relaxation stress vs. hold time data obtained using Model-II follow the experimental data more closely compared to those derived from the Model-I.
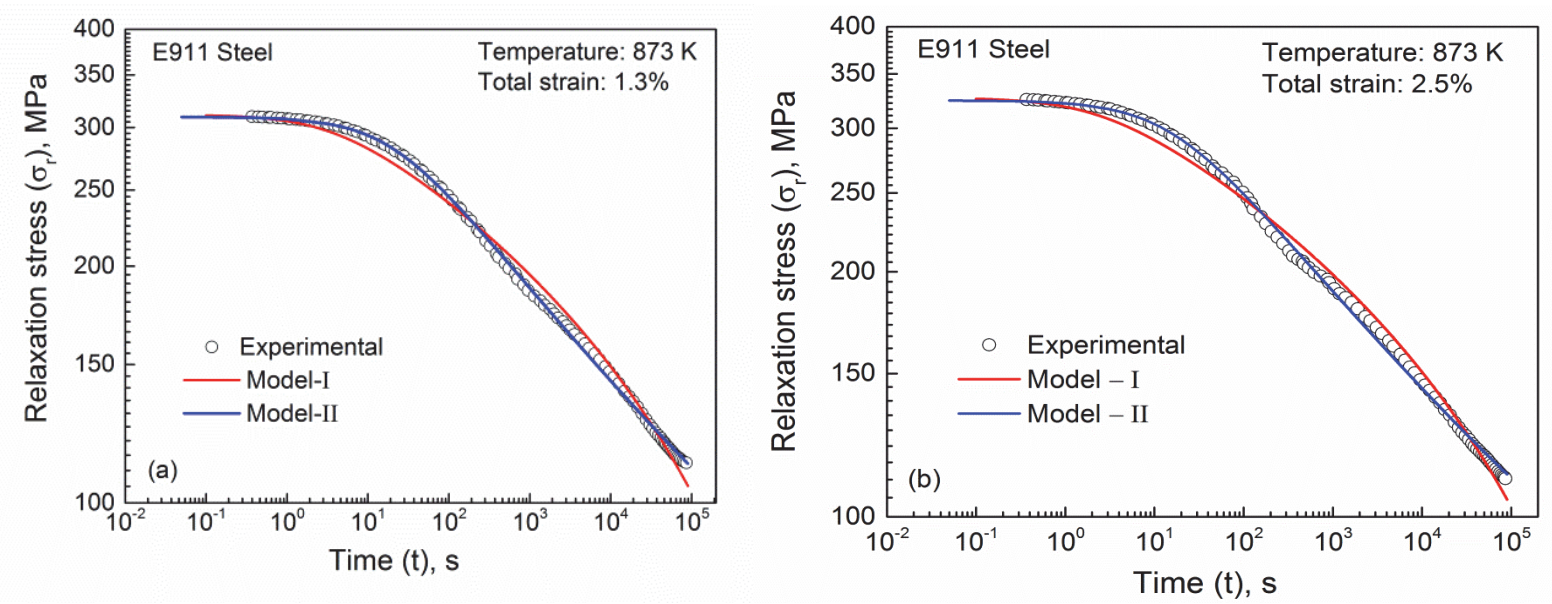

Figure 4: Variations in experimental relaxation stress $\left(\sigma_{\mathrm{r}}\right)$ with hold time $(\mathrm{t})$ for a) $1.3 \%$ and b) $2.5 \%$ strain holds. The predicted $\sigma_{\mathrm{r}}$ vs. $\mathrm{t}$ data using Model-I and Model-II have also been superimposed for both strain hold conditions.

The variations in the deviation of stress values as $\Delta \sigma_{\mathrm{r}}=\sigma_{\mathrm{r} \text { exp }}-\sigma_{\mathrm{r} \text {,pred }}$ with time exhibit lower values for Model-II over Model-I. This further suggested statistical suitability of the Model-II for describing stress-relaxation behaviour of tempered martensitic 9\% Cr steels (Fig. 5). Based on experimental observations in 9\% Cr steels, it has been shown that the subgrain coarsening accompanied with decrease in dislocation density remains dominant during inelastic deformation under stress-relaxation conditions at elevated temperatures [12,13]. The reported increase in lath width or subgrain size indicated the increase in inter-barrier spacing $(\lambda)$ for $9 \% \mathrm{Cr}$ steels during stress-relaxation. It is known that inter-barrier spacing $(\lambda)$ and activation volume $(\Delta \mathrm{V})$ is inversely related to internal stress. Therefore, the variations in internal stress as well as activation volume with the hold time are expected for $9 \% \mathrm{Cr}$ steels. From the microstructural aspects, it is evident that Feltham relation [4] involving constancy in internal stress and activation volume is not applicable for describing the stress-relaxation behaviour of E911 steel. However, Model-II has been able to predict the evolution of internal stress, effective stress and relaxation stress with respect to hold time. This is shown in Fig. 6 for the strain hold of 1.3\% as an example. Based on Freidel statistics [14], the internal stress and effective stress can be used to evaluate the inter-barrier spacing and activation volume. The relationships are given as

$$
\lambda=\frac{M \mu b}{2 \pi \sigma_{i}}
$$

and

$$
\Delta V=b^{3}\left[\frac{M \mu}{\left(\left(2 \pi \sigma_{i}\right)^{2} \sigma_{e}\right)^{1 / 3}}\right]
$$

where ' $\mathrm{b}$ ' is the Burgers vector. Fig. 7 depicts the evolution of inter-barrier spacing and activation volume with the hold time. The observed increase in inter-barrier spacing and activation volume confirms that continual substructural coarsening of E911 steel during stress-relaxation. The comments related to the evolution of internal stress $\left(\sigma_{\mathrm{i}}\right)$ and its dependence on relaxation stress $\left(\sigma_{\mathrm{r}}\right)$ following Eqn. (9) is noteworthy. In several metals and alloys, based on stress change experiments during steady state creep, it has been observed that the relationship between internal stress and applied stress obeys power law. The exponent values in the range 0.7-1.0 were reported for $\mathrm{Cd}, \mathrm{Mg}, \mathrm{Al}-\mathrm{Li}$ and $\mathrm{Al}-\mathrm{Mg}$ alloys [15-18]. The observed power law exponent $\mathrm{m}=0.81$ for E911 steel is in agreement with those values observed for different materials [15-18]. Based on internal variable approach, it has also been found that the variations in $\sigma_{\mathrm{i}} / \sigma_{\mathrm{a}}$ (where $\sigma_{\mathrm{a}}$ is the applied stress) with $\sigma_{\mathrm{a}}$ exhibited power law relation as $\sigma_{\mathrm{i}} / \sigma_{\mathrm{a}} \sim \sigma_{\mathrm{a}}^{-0.21}$ or $\sigma_{\mathrm{i}}=2.22 \sigma_{\mathrm{a}}^{0.79}$ for P9 steel during secondary creep deformation [8,9]. The equivalence between the results obtained from stress relaxation tests and monotonic creep tests is 
reported in literature for $9 \% \mathrm{Cr}$ steels [13,19]. It was demonstrated that the stress exponent values obtained from stressrelaxation data for $9 \% \mathrm{Cr}$ steel compared favourably with monotonic creep tests and falls in dislocation creep regime [19]. Since dislocation creep is the main dominating mechanism for $9 \% \mathrm{Cr}$ steels, the power law dependency between variations of internal stress and relaxation stress proposed by Argon and Takeuchi [10] has been implemented in the present investigation. The reported value of 0.79 for P9 steel is close to the observed exponent value of 0.81 for E911 steel (Tab. 2). It indicates that the power law relation between internal stress and applied stress observed for monotonic creep can be successfully implemented for stress-relaxation studies in 9\% $\mathrm{Cr}$ steels. Moreover, present investigations clearly suggested that Model-II provides better description of stress-relaxation behaviour of $9 \%$ Cr steels than Feltham model i.e. Model-I.

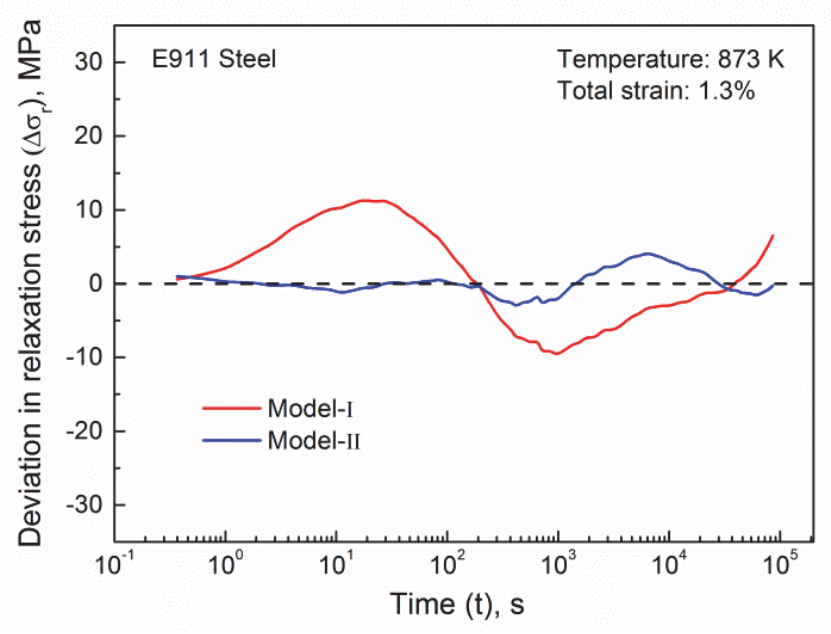

Figure 5: Deviation in predicated relaxation stress with reference to the experimental value i.e. $\Delta \sigma_{\mathrm{r}}$ as a function of hold time.

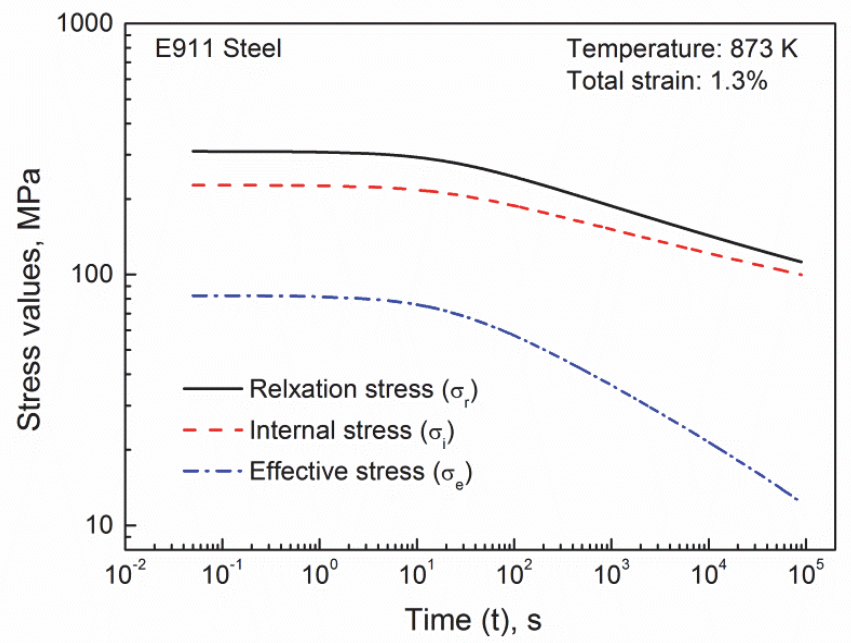

Figure 6: Variations in relaxation stress $\left(\sigma_{\mathrm{r}}\right)$, internal stress $\left(\sigma_{\mathrm{i}}\right)$ and effective stress $\left(\sigma_{\mathrm{e}}\right)$ with hold time $(\mathrm{t})$ for the strain hold $1.3 \%$ for E911 steel at $873 \mathrm{~K}$.

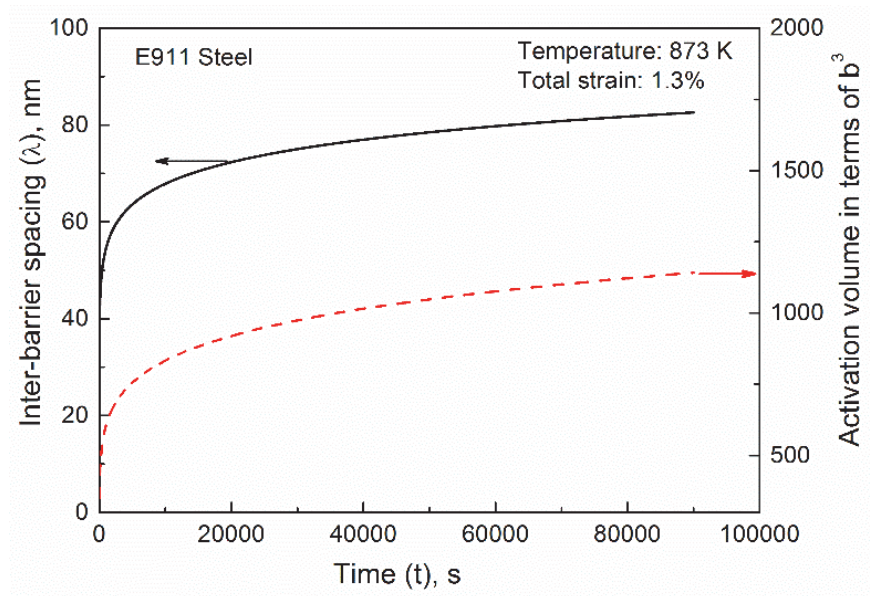

Figure 7: Variations in inter-barrier spacing $(\lambda)$ and activation volume $(\Delta \mathrm{V})$ with hold time $(\mathrm{t})$ for the strain hold $1.3 \%$ for E911 steel at $873 \mathrm{~K}$.

\section{CONCLUSIONS}

omparative evaluation of two physically based models has been performed for the description of stress-relaxation
behaviour of E911 steel for the strain holds of 1.3 and $2.5 \%$ at $873 \mathrm{~K}$. As compared to Model-I (Feltham model),
Model-II proposed by Christopher and Choudhary provides better prediction towards relaxation stress vs. hold 
time data of E911 steel. From the microstructural aspects, it is evident that Feltham relation involving constancy in internal stress and activation volume is not applicable for describing the stress-relaxation behaviour of E911 steel. Contrary to this, Model-II can capable to capture the evolution of internal and effective stresses, activation volume and inter-barrier spacing with time for E911 steel during deformation under stress-relaxation. The predicted increase in interbarrier spacing and activation volume with hold time confirms that continual substructural coarsening of E911 steel during stress-relaxation.

\section{REFERENCES}

[1] Di Gianfrancesco, A., Cipolla, L., Cirilli, F., Cumino, G. and Caminada, S. (2005). Microstructural stability and creep data assessment of Tenaris Grades 91 and 911, In Proceedings of $1^{\text {th }}$ International Conference Super-High Strength Steels, pp. 2-4.

[2] Manjoine, M. J. and Voorhees, H. R. (1982). Compilation of stress-relaxation data for engineering alloys, ASTM. DOI: $10.1520 /$ MNL11954D.

[3] Dotseneo, V.I. (1979). Stress relaxation in crystals, Phys. status solidi B, 93, pp. 11-43. DOI: $10.1002 /$ pssb.2220930102.

[4] Feltham, P. (1963). Stress relaxation in magnesium at low temperatures, Phys. status solidi B, 3, pp. 1340-1346. DOI: $10.1002 /$ pssb.19630030805.

[5] McCarthy, P.R., Robertson, D.G., Orr, J. and Strang, A. (2000). Recent development in stress relaxation methodologies within Europe, Key Eng. Mater., 171-174, pp. 9-16.

DOI: $10.4028 /$ www.scientific.net/KEM.171-174.9.

[6] Humphries, S.R., Snowden, K.U. and Yeung, W. (2010). The effect of repeated loadings on the stress relaxation properties of $2.25 \mathrm{Cr}-1 \mathrm{Mo}$ steel at $550{ }^{\circ} \mathrm{C}$ and the influence on the Feltham ' $\mathrm{a}$ ' and 'b' parameters, Mater. Sci. Eng., A, 527, pp. 3240-3244. DOI: 10.1016/j.msea.2010.02.011.

[7] Trojanová, Z., Máthis, K., Lukác, P., Németh, G. and Chmelík, F. (2011). Internal stress and thermally activated dislocation motion in an AZ63 magnesium alloy, Mater. Chem. Phys., 130, pp. 1146-1150.

DOI: $10.1016 /$ j.matchemphys.2011.08.045.

[8] Christopher, J. and Choudhary, B. K. (2018). Constitutive modelling of stress-relaxation behaviour of tempered martensitic P91 steel using sine hyperbolic rate law, Mater. Chem. Phys., 205, pp. 442-451.

DOI: $10.1016 /$ j.matchemphys.2017.11.053.

[9] Christopher, J. and Choudhary, B. K. (2016). Constitutive description of primary and steady-state creep deformation behaviour of tempered martensitic 9Cr-1Mo steel, Philos. Mag. A, 96(21), pp. 2256-2279.

DOI: $10.1080 / 14786435.2016 .1197435$.

[10] Argon, A.S. and Takeuchi, S. (1981). Internal stresses in power-law creep, Acta Metall., 29, pp. $1877-1884$. DOI: 10.1016/0001-6160(81)90113-9.

[11] Nakajima, T., Spigarelli, S., Evangelista, E., \& Endo, T. (2003). Strain enhanced growth of precipitates during creep of T91, Mater. Trans., 44(9), pp. 1802-1808. DOI: 10.2320/matertrans.44.1802.

[12] Bose, S. C., Singh, K., Swaminathan, J. and Sarma, D. S. (2004). Prediction of creep life of X10CrMoVNbN-91 (P91) steel through short term stress relaxation test methodology, Mater. Sci. Technol., 20(10), pp. 1290-1296.

DOI: $10.1179 / 026708304225022304$.

[13] Guguloth, K., Swaminathan, J., Roy, N. and Ghosh, R. N. (2017). Uniaxial creep and stress relaxation behavior of modified 9Cr-1Mo steel, Mater. Sci. Eng., A, 684, pp. 683-696. DOI: 10.1016/j.msea.2016.12.090.

[14] Friedel, J. (1964). Dislocations. Pergamon Press, Oxford.

[15] Northwood, D.O. and Smith, I.O. (1984). Steady-State Creep and Strain Transients for Stress-Dip Tests in Polycrystalline Magnesium at $300^{\circ}$ C, Phys. status solidi A, 85, pp.149-158. DOI: 10.1002/pssa.2210850117.

[16] Northwood, D. O., Moerner, L. and Smith, I. O. (1985). Effect of magnesium content on the stress exponent and effective stress in the steady state creep of Al-Mg alloys, J. Mater. Sci., 20(5), pp. 1683-1692. DOI: $10.1007 /$ bf00555272.

[17] Northwood, D.O. and Smith, I.O. (1986). Stress change tests during the steady .state creep of aluminum alloy 3004 at $300{ }^{\circ}$ C, Mater. Sci. Eng., 79, pp.175-182. DOI: 10.1016/0025-5416(86)90402-7

[18] Northwood, D.O. and Smith, I.O. (1986). Internal and Effective Stresses in the Steady-State Creep of Polycrystalline Cadmium at 0.5 Tm, Phys. status solidi A, 98, pp.163-169. DOI: 10.1002/pssa.2210980117. 
[19] Praveen, C., Christopher, J. and Choudhary B. K. (2017). Critical Assessment of Short-Term Stress-Relaxation Studies for the Prediction of Creep Properties of P91 Steel, Trans. Ind. Inst. Met., 70 (3), pp. 655-660.

DOI:10.1007/s12666-017-1090-1.

\section{NOMENCLATURE}

$\dot{\varepsilon}_{\mathrm{t}} \quad$ Total applied strain rate

$\dot{\varepsilon}_{\mathrm{e}} \quad$ Elastic strain rate

$\dot{\varepsilon}_{\text {in }} \quad$ Inelasticstrain rate

t Hold time

$\sigma_{\mathrm{r}} \quad$ Relaxation stress

C Effective modulus of sample-machine system

$\dot{\varepsilon}_{0} \quad$ Characteristic strain rate

$\rho_{\mathrm{m}} \quad$ Mobile dislocation density

Q Activation energy

$\sigma_{\mathrm{i}} \quad$ Internal stress

$\Delta \mathrm{V} \quad$ Activation volume

$\mathrm{T}$ Temperature b Burgers vector

M Taylorsfactor

$\mathrm{s}, \eta$ and $\mathrm{t}_{0}$ Constants involved in Model-I

$\sigma_{\mathrm{r} 0} \quad$ Initial relaxation stress

$\sigma_{\mathrm{i} 0} \quad$ Initial internal stress

$\mathrm{m} \quad$ Power law exponent

h Power law co-efficient

$\mu \quad$ Shear modulus

R Gasconstant

$v_{D} \quad$ Debye frequency

k Boltzmann's constant 